\title{
Erratum to: Higher Prevalence of Obesity in Gastric Cardia Adenocarcinoma Compared to Gastric Non-Cardia Adenocarcinoma
}

Yuri Cho $\cdot$ Dong Ho Lee $\cdot$ Hong Sang Oh $\cdot$ Ji Yeon Seo $\cdot$ Dong Hyeon Lee

Nayoung Kim - Sook Hyang Jeong • Jin Wook Kim • Jin Hyuk Hwang •

Young Soo Park $\cdot$ Sang Hyub Lee $\cdot$ Cheol Min Shin $\cdot$ Hyun Jin Jo •

Hyun Chae Jung $\cdot$ Yong Bum Yoon $\cdot$ In Sung Song

Published online: 30 May 2012

(C) Springer Science+Business Media, LLC 2012

\section{Erratum to: Dig Dis Sci}

DOI 10.1007/s10620-012-2095-6

Yuri Cho is identified as the corresponding author of the paper, but the actual corresponding author is Dong Ho Lee.

The online version of the original article can be found under doi:10.1007/s10620-012-2095-6.

Y. Cho $\cdot$ H. S. Oh · J. Y. Seo - D. H. Lee .

H. C. Jung · Y. B. Yoon · I. S. Song

Department of Internal Medicine, Seoul National University

College of Medicine, Seoul, Korea

e-mail: presh_yuri@hanmail.net

Present Address:

Y. Cho

Hanshin 19th apartment, Jamwon-dong, Seocho-gu,

Seoul 331-404, Korea

D. H. Lee $(\bowtie) \cdot$ N. Kim · S. H. Jeong ·

J. W. Kim · J. H. Hwang · Y. S. Park · S. H. Lee ·

C. M. Shin - H. J. Jo

Department of Internal Medicine, Seoul National University

Bundang Hospital, Seongnam, Gyeonggi-do, Korea

e-mail: dhljohn@snubh.org 